\title{
A scoping review and assessment of essential elements of shared decision-making of parent-involved interventions in child and adolescent mental health
}

\author{
Shaun Liverpool ${ }^{1,3} \cdot$ Brent Pereira $^{2} \cdot$ Daniel Hayes $^{1,3} \cdot$ Miranda Wolpert $^{3} \cdot$ Julian Edbrooke-Childs $^{1,3}$
}

Received: 1 August 2019 / Accepted: 6 April 2020 / Published online: 16 April 2020

(c) The Author(s) 2020

\begin{abstract}
Parents play a critical role in child and adolescent mental health care and treatment. With the increasing implementation of shared decision-making (SDM) across health settings, there is a growing need to understand the decision support interventions used to promote SDM in child and adolescent mental health services (CAMHS). The overall aim of this review is to identify and examine the existing decision support interventions available for parents. A broad search was conducted using the key concepts "shared decision-making", "parents" and "child and adolescent mental health". Five electronic databases were searched: PsycInfo, Embase, Medline, Web of Science and the Cochrane Library. In addition to these relevant databases, we searched the Ottawa's Inventory of Decision Aids, Children's Hospital of Eastern Ontario website, Google, Google Play and known CAMHS' websites. The search identified 23 interventions available for use with parents. These interventions targeted parents providing care for children with ADHD, ASD, emotional and behavioural problems including depression (EBD), self-harm or universal mental health care. Various modalities including face-to-face, digital and paper-based versions were adopted. The majority of the interventions were able to "present options" (87\%) and "discuss the pros and cons" (83\%) of treatment. Time, accessibility and appropriateness of the intervention emerged as factors influencing usage and implementation of interventions. Our findings suggest that SDM interventions involving parents have been implemented differently across various presenting mental health difficulties in CAMHS. This review brings awareness of existing parent-involved interventions and has implications for the development, implementation and usage of new interventions.
\end{abstract}

$\begin{array}{ll}\text { Abbreviations } \\ \text { ADHD } & \text { Attention deficit hyperactivity disorder } \\ \text { ASD } & \text { Autism spectrum disorder } \\ \text { CAMH } & \text { Children and adolescents mental health } \\ \text { CAMHS } & \text { Child and adolescent mental health services } \\ \text { CBT } & \begin{array}{l}\text { Cognitive behavioural therapy } \\ \text { EBD }\end{array} \\ & \begin{array}{l}\text { Emotional and behavioural problems including } \\ \text { depression }\end{array} \\ \text { IPDAS } & \text { International Patient Decision Aid Standards } \\ \text { NHS } & \text { National Health Service } \\ \text { PCC } & \text { Person-centred care } \\ \text { PFTA } & \text { Preparing for the appointment }\end{array}$

Shaun Liverpool

shaun.liverpool.14@ucl.ac.uk

1 Evidence-Based Practice Unit, Anna Freud National Centre for Children and Families, 4-8 Rodney Street, London, UK

2 The Chicago School of Professional Psychology, Chicago, USA

3 University College London, London, UK
QPL Question prompt list

RCT Randomised controlled trial

SDM Shared decision-making

\section{Introduction}

A scoping review and assessment of essential elements of shared decision-making of parent-involved interventions in child and adolescent mental health

Mental health care and treatment decisions for children and adolescents can be challenging. In child and adolescent mental health services (CAMHS), primary caregivers (from here on referred to as parents) are confronted with many decisions. These decisions include how, when, and where to seek help [1]; agreeing on treatment options when more than one treatment option is available [2,3]; agreeing on the goals of treatment $[4,5]$; and agreeing on diagnostic tests [6]. For parents involved in the decision-making process, the journey can be complicated by a range of factors such as low levels of agreement between parents, children, and 
clinicians [7-18]. Decision-makers may hold different values that bring conflicting views on treatment and care options [19]. As a result, researchers and practitioners suggest that the implementation of shared decision-making (SDM) in CAMHS may be one approach to reduce treatment disagreements [20-22].

SDM is defined as the communication process that allows service users and service providers to collaborate when making care and treatment decisions [23]. SDM is considered an optimal standard to improve person-centred care and health care quality [24-26]. As such, there have been a number of initiatives to engage patients in SDM. However, in caring for children and adolescents, the decision-making process can be unique as clinicians, parents, and sometimes children are involved. Understanding the triangular relational structure $[23,27]$ can have implications on the implementation and development of decision support interventions.

Involving parents in decisions in CAMHS may be particularly important as many child mental health interventions require direct parent involvement. Parents may be involved as co-patients (family therapy), co-therapists [Cognitive Behaviour Therapy (CBT)], or be the direct focus of the intervention (parent training) [28, 29]. Yet to date, there has been little research on SDM involving parents in child mental health $[22,30]$.

A recent scoping review highlighted six approaches used in decision support interventions in CAMHS. These included: therapeutic techniques, decision aids, psychoeducational information, goal setting, discussion prompts, and mobilising patients to engage [30]. Of the 22 interventions identified in that review, 12 involved parents. However, the authors' primary aim was not to investigate parents' interventions in any detail but to understand what approaches existed across CAMHS. Due to the rapid increase and interest in SDM, a further review is needed to highlight specific components, such as modes of delivery and techniques that are used with various populations to promote SDM behaviour.

Gondek et al. [31] reviewed factors influencing personcentred care in CAMHS and highlighted that parental involvement positively influenced person-centred care. The authors explored published empirical studies elaborating on facilitators and barriers to person-centred care. However, $\mathrm{SDM}$ is a central feature of person-centred care and may present its unique influencing factors. Therefore, it is necessary to understand whether these same barriers extend to the implementation and usage of SDM interventions. Subsequent research in SDM confirms this, with young people stating that when decisions were difficult or when young people lacked capacity, parental involvement was seen as positive [85]. Hence, it was necessary to build on that review, expanding the literature search to examine the grey literature or development studies on decision support interventions.

One important step in offering decision support to parents is first to assess the decision to be made and the associated decision-making needs [32]. Providing information alone is unlikely to fully address the decision support needs of parents [33]. In attempts to promote parental involvement in child mental health decision-making, some concepts and evidence have been adopted from adult health care [34]. However, in adult settings, the decisions are usually twoway between clinician and client. In the case of a triad, the clinician, client, and caregiver/partner are usually all adults. Therefore, within CAMHS, approaches need to be tailored to accommodate varying levels of involvement depending on the child's age and capacity. Therefore, identifying appropriate decision aids would be an important step to an effective decision-making process [32].

Findings from a qualitative study indicated that the implementation of SDM in CAMHS is effortful and while tools may help support SDM, clinicians need to be allowed to use the tools flexibly [35]. Similarly, decision aids in practice have been met with various challenges [31]. Clinicians need to balance the needs of children and their parents and have complex conversations [22]. Clinicians also report being limited in their use of SDM due to service limitations, including a lack of available options, and sometimes needing to overrule decisions made by the young person due to capacity issues [86]. Therefore, examining current approaches to support parents' involvement in SDM in CAMHS, and exploring ways to increase flexibility and usefulness of SDM, is required.

In this review, we examined the extent to which decision support interventions addressed the nine essential elements of SDM. Makoul and Clayman [36] highlighted that for SDM to occur the process should include nine essential elements: patient values/preferences, options, professional knowledge/recommendations, make or explicitly defer a decision, define/explain the problem, check/clarify understanding, explore benefits/risks, discuss patient's ability/selfefficacy, and arrange follow-up. Therefore, each included intervention was assessed based on the comprehensiveness of the intervention to demonstrate these elements of SDM.

Similar reviews explored SDM from a wider perspective: interventions targeting children and clinicians, or targeting physical health [30, 31, 37, 38]. An updated review in the area of SDM in CAMHS, which focuses specifically on parent-targeted or parent-involved interventions can highlight important themes to understand parents' involvement in the decision-making process. This is important as parents report having a better understanding of their child's difficulties [39], and feeling better equipped to manage their child's mental health [31] when allowed to participate in SDM. 
This study aimed to conduct a systematic scoping review to identify parent-involved SDM interventions in CAMHS and assess essential elements of SDM in these interventions. A secondary objective was to explore the factors associated with implementing SDM interventions in CAMH settings.

\section{Research questions}

The following research questions were developed to address our aims:

What decision support interventions are available for parents of children accessing child and adolescent mental health services?

Which of the SDM elements are addressed in these interventions?

What are the barriers and facilitators to usage and implementation?

What is the evidence for usefulness and acceptability of these interventions?

\section{Method}

The methods for this review were guided by the standard review methodology [40] and those described by Arksey and O'Malley [41].

\section{Identifying relevant studies}

The following electronic databases were searched until March 2018: PsycInfo, Embase (Ovid version), Medline (Ovid version), Web of Science and the Cochrane Library, in addition to reference lists and International Shared Decision Making (ISDM2017) conference materials. The three concepts driving the searches included "SDM", "parents" and "CAMHS".

In addition to the relevant databases, we searched the Ottawa decision aid list, Children's Hospital of Eastern Ontario (CHEO) website, Google, Google Play store and known children's mental health services' websites. Upon completion, the empirical studies found were documented and references were imported into EndNote and all other relevant records (i.e. interventions not associated with any research literature) were added to an Excel spreadsheet.

\section{Selecting studies}

The eligibility criteria (see Table 1) were developed alongside the research questions. Before the study began, it was agreed by SL, JEC, and MW that the elements of SDM by Makoul and Clayman [36] would be used to assess the extent to which interventions included essential elements of SDM, similar to the review by Cheng et al. [30].

Firstly, the eligibility criteria were piloted on a random sample of five papers by two independent reviewers (SL and $\mathrm{BP})$. This was necessary to refine and clarify the inclusion criteria and ensure that they could be applied consistently by

Table 1 Inclusion/Exclusion Criteria

\begin{tabular}{|c|c|c|}
\hline & Inclusion criteria & Exclusion criteria \\
\hline Population & $\begin{array}{l}\text { Interventions should target persons identified as being a parent/ } \\
\text { primary caregiver/legal guardian of a child with mental health } \\
\text { problems or currently accessing child and adolescent mental } \\
\text { health services (CAMHS) }\end{array}$ & $\begin{array}{l}\text { Studies with interventions that target the parents' illness (e.g. } \\
\text { how a parent with breast cancer should disclose to their child } \\
\text { who is at risk for depression) } \\
\text { Studies/ Interventions where the parents/caregivers are not } \\
\text { active participants in the decision-making process }\end{array}$ \\
\hline Intervention & $\begin{array}{l}\text { Any family/parent- targeted or parent -involved intervention } \\
\text { tool (e.g. online decision aids, mobile applications and parent } \\
\text { training) used by the selected population over any period of } \\
\text { time } \\
\text { Interventions targeted at parents/caregivers but aimed at being } \\
\text { beneficial to decisions around the child's mental health }\end{array}$ & $\begin{array}{l}\text { The intervention is aimed only at patient medical records (e.g. } \\
\text { databases to allow ease of access by the parents of children in } \\
\text { CAMHs) } \\
\text { Interventions aimed at groups with physical diagnosis (e.g. } \\
\text { interventions for children experiencing anxieties of taking } \\
\text { insulin) } \\
\text { Papers where the interventions are targeted at the child and/or } \\
\text { clinician only and excluded the caregivers }\end{array}$ \\
\hline Comparator & N/A & N/A \\
\hline Outcome & $\begin{array}{l}\text { Intervention should aim to change levels of parental/caregiver } \\
\text { involvement in their child's treatment decision }\end{array}$ & $\begin{array}{l}\text { Evaluating other health issues or outcomes other than mental } \\
\text { health only (e.g. diabetes) }\end{array}$ \\
\hline Study design & $\begin{array}{l}\text { All study types that involve the development and testing of the } \\
\text { intervention and published in the English Language }\end{array}$ & \\
\hline
\end{tabular}


more than one person and reduce the possibility of rejecting relevant reports [42].

Stage 1: Once all duplications were removed, the remaining records were screened by title only and irrelevant records were excluded (i.e. records identifying physical health, e.g. asthma, or non-CAMHS settings, e.g. palliative care).

Stage 2: Abstracts were read and further records not meeting inclusion criteria were excluded. Stage 3: The remaining full-text reports and records identified through the grey literature were screened for inclusion. The most frequent reason for exclusion at this stage was the intervention not meeting any of the essential elements of SDM. All searching and screening were conducted by SL and the articles being considered for final inclusion were screened by BP to eliminate the possibility of paper selection bias. There were no major disagreements regarding inclusion/exclusion judgement and through discussion a consensus was reached to include all selected articles.

\section{Data extraction process}

The data extraction sheet was developed based on those used in similar systematic reviews [30, 31, 37, 38]. The data were then extracted from all records being included by SL and verified by BP. Extracted variables included authors, year, target population, description of the intervention, modality, barriers and facilitators identified, study design and outcome (where applicable). Disagreements between the two investigators SL and BP regarding data extraction were resolved through discussions. Where differences in opinions for data extraction arose, a consultation was sought from JEC. A difference in opinion occurred for 3 interventions (1.3\%), mainly around the identification of barriers and facilitators. We contacted two authors $[43,44]$ and obtained further information.

\section{Assessment of essential elements of SDM}

The assessment of the essential elements of SDM was reported as per the number of elements of SDM characteristics met. For example, in high-SDM interventions, a higher number (7-9) of the essential elements were met, medium-SDM interventions met 4-6 of the essential elements, and low-SDM interventions met 1-3 of the essential elements. The assessments were conducted collaboratively by SL and JEC and discussed in detail before any consensus was reached. The nine elements defining SDM, according to Makoul and Clayman [36], have been used in previous studies to evaluate decision support tools $[30,87]$ and is one of the most frequently cited SDM models. This model was developed based on a synthesis of other SDM models and, therefore, provides a broad description of the SDM process which allows for comparisons among the identified SDM interventions [85].

\section{Data synthesis}

The limited number of eligible RCTs and heterogeneity in the intervention type, study design, and outcomes precluded the pooling of results for a meta-analysis [45]. Therefore, a narrative synthesis approach [46] was used to address our research questions. For research questions 1 and 2, we utilised data from all the interventions identified $(n=23)$. To address research questions 3 and 4, it was only possible to include interventions that were evaluated $(n=15)$.

\section{Results}

The database searching identified 20,112 records: PsychInfo $=3345$, Embase $=7099$, Medline $=5203$, Web of Science $=3308$ and Cochrane Library $=1157$. An additional 14 records were identified through other sources in March 2018 and updated 14th December 2018: Ottawa decision aid list $=4$, Reference trolling $=2$, Children's Hospital of Eastern Ontario $(\mathrm{CHEO})=3$, Google $=5$. The preferred reporting items for systematic reviews and metaanalyses (PRISMA) flow diagram (Fig. 1) depicts the flow of information through the different phases of this review and reports the number of records identified, included, and excluded.

A total of 31 records were identified for inclusion. These include 23 research articles with publication dates ranging from 1994 to 2018 and 8 interventions without any associated research publication. The interventions with development dates were developed from 2010 onwards. The 31 records identified (inclusive of development and evaluation studies), map onto 23 interventions for use by parents of children with mental health difficulties. Details related to the interventions are provided in Table 2.

Question \#1: What decision support interventions are available for parents of children accessing mental health services?

The 23 interventions identified in this review were: (1) Asking Questions about ADHD-Question Prompt List (QPL), (2) ADHD SDM Intervention, (3) The Shared Decision Framework, (4) Preparing for the Appointment (PFTA) worksheet, (5) Counseling in Dialogue, (6) Families First of Essex County, (7) Decision Aid for ADHD, (8) ADHD Preference and Goal Instrument, (9) Giving Parents a Choice, (10) ASD-Specific Medical Home, (11) Interactive Early Intervention Patient Decision Aid for Parents, (12) Coaching in deliberation, (13) i-THRIVE Grids, (14) Option Grid 
PRISMA FLOW CHART

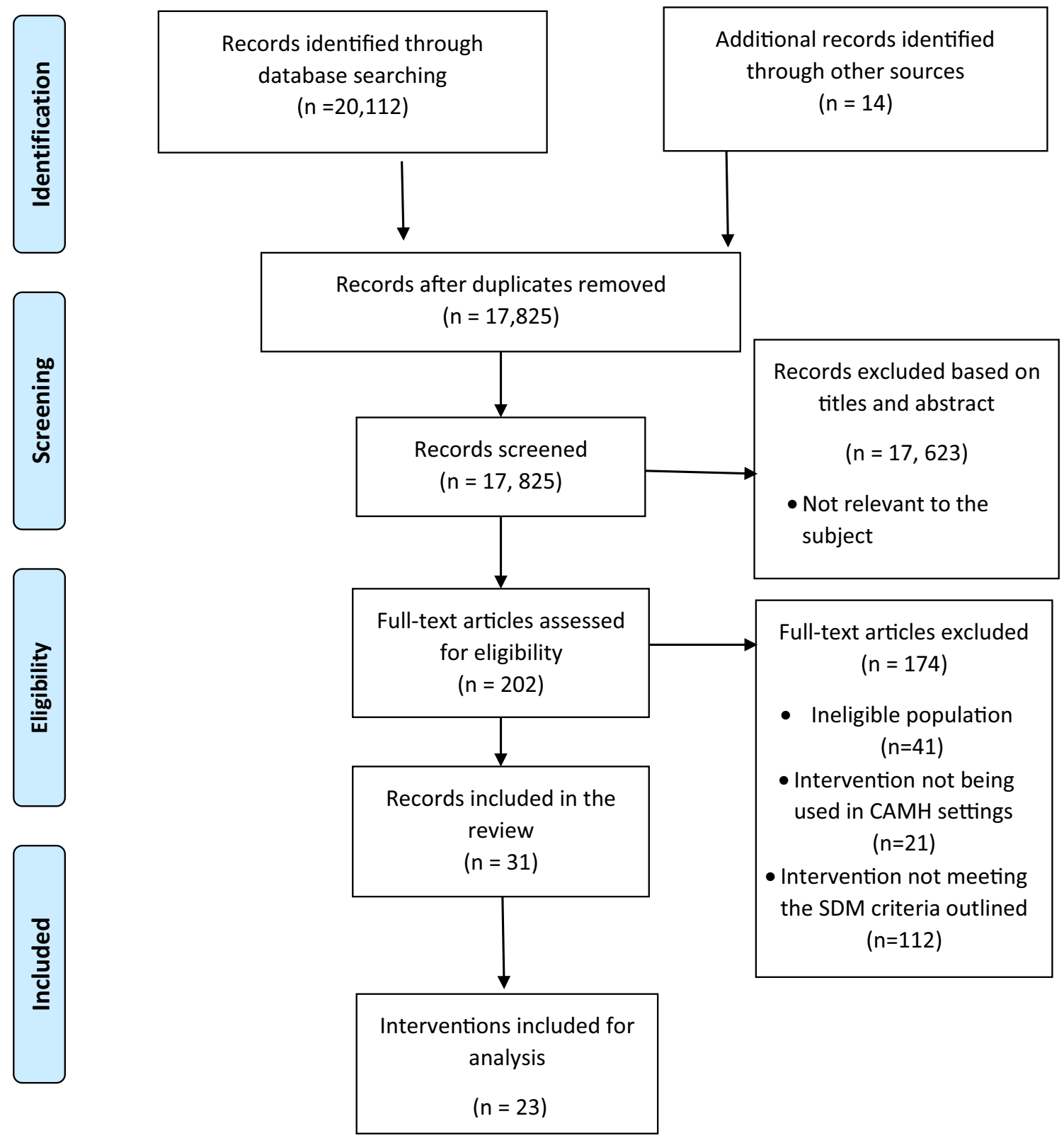

Fig. 1 PRISMA flow diagram of study selection (adapted from Moher et al. 2009)

treatment decision aid, (15) Guided access DVD, (16) A checklist for parents with children with mental health problems, (17) Autism: Should my Child Take Medicine for Challenging Behaviour?, (18) Depression: Should My Child Take Medicine to treat Depression?, (19) ADHD: Should My Child Take Medicine for ADHD?, (20) Goal progress/ record/rating Charts, (21) Treatment Options for ADHD in Children and Teens: A review of research for parents and caregivers, (22) Is this guide right for the child in my care?, and (23) Ottawa Family Decision Guide.
Interventions were supported by various modalities and accessible by one or more of the following formats: $43 \%$ (10) paper-based, 39\% (9) digital, 17\% (4) multimodal, and $9 \%$ (2) face-to-face. The majority of the interventions were available online for print, web-use, or the contact details were available to seek authors' permission to use. The primary foci of the interventions were to support treatment decisions, highlight goals, choices and preferences, provide information, and facilitate overall doctor-client communication. 


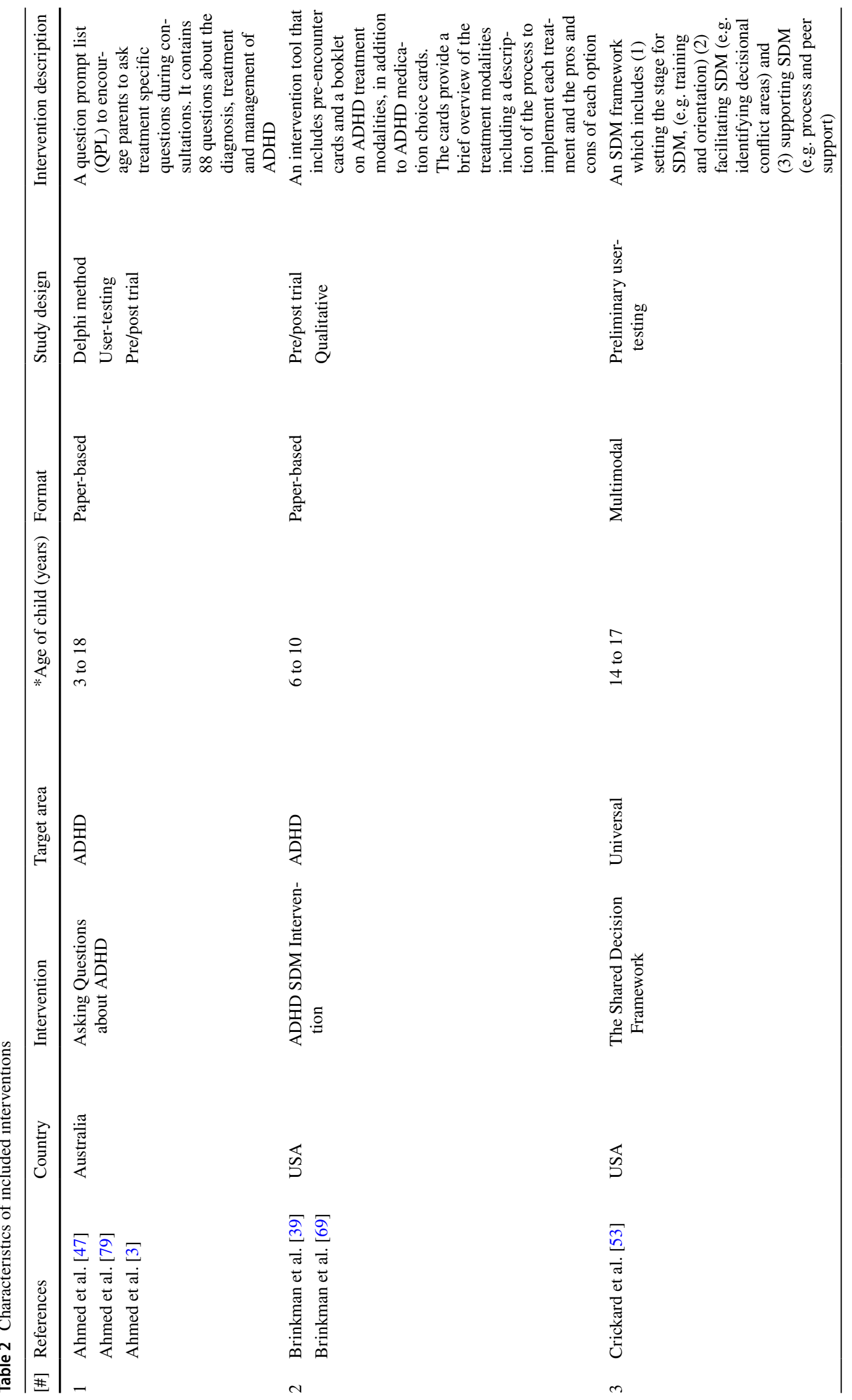




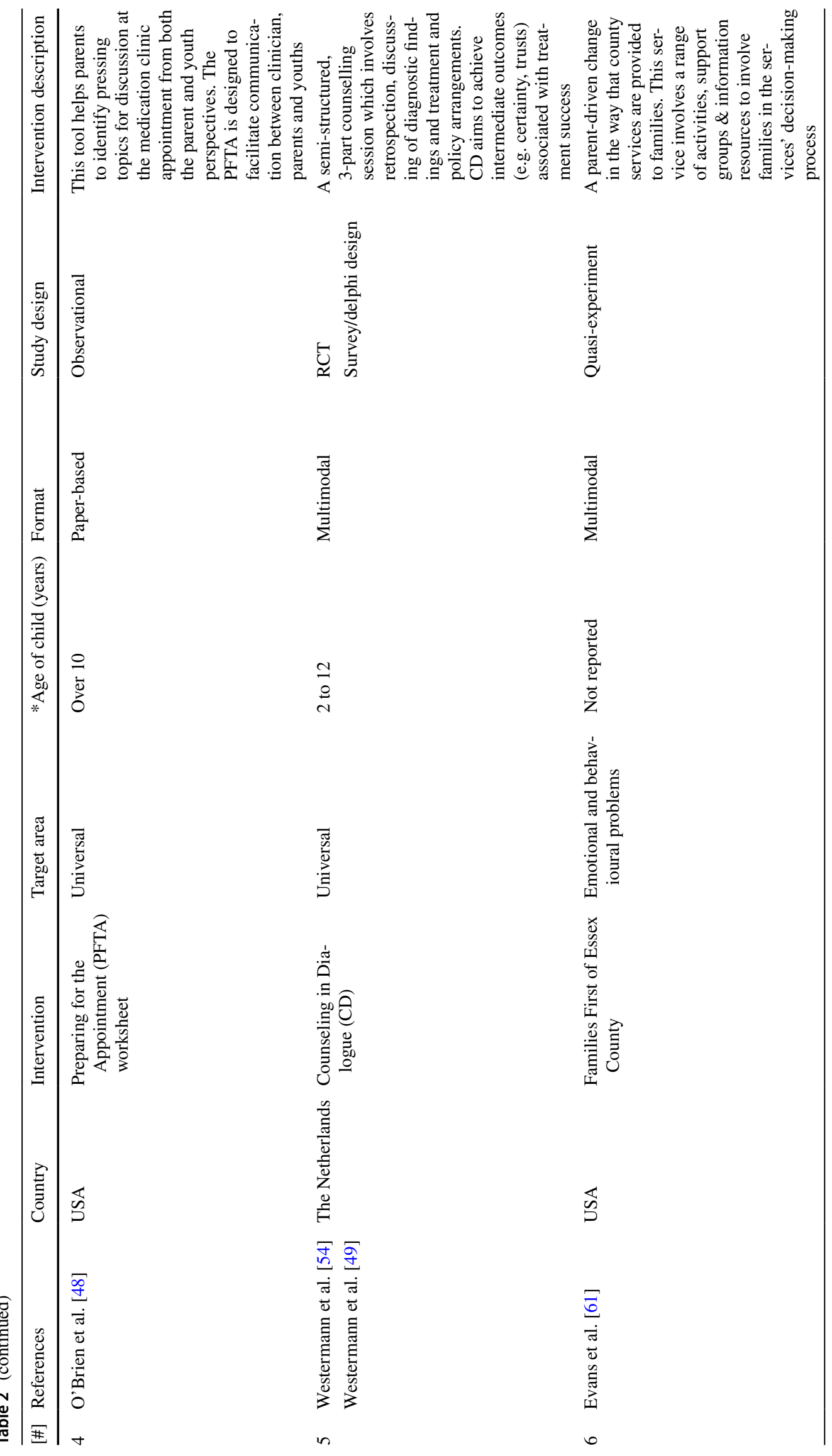




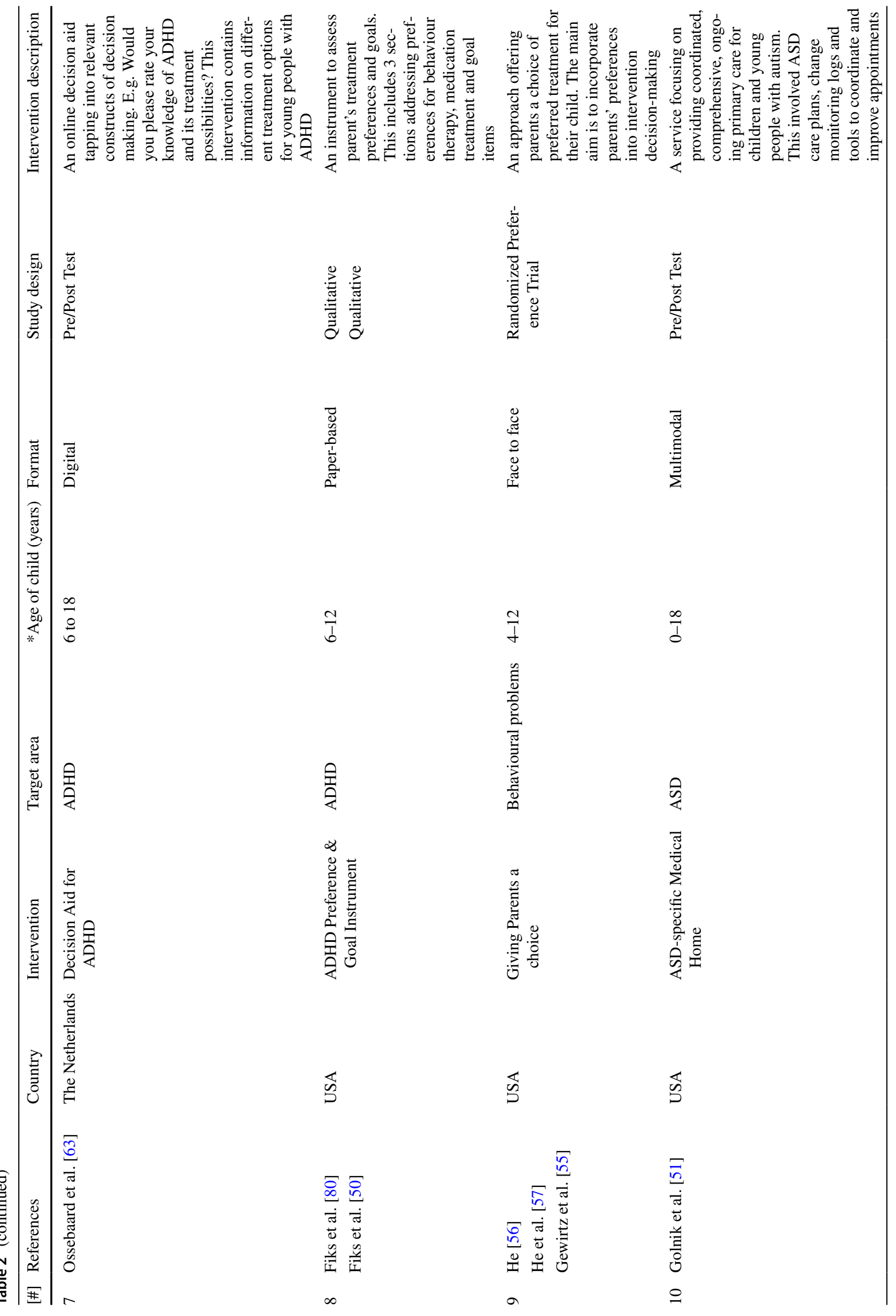




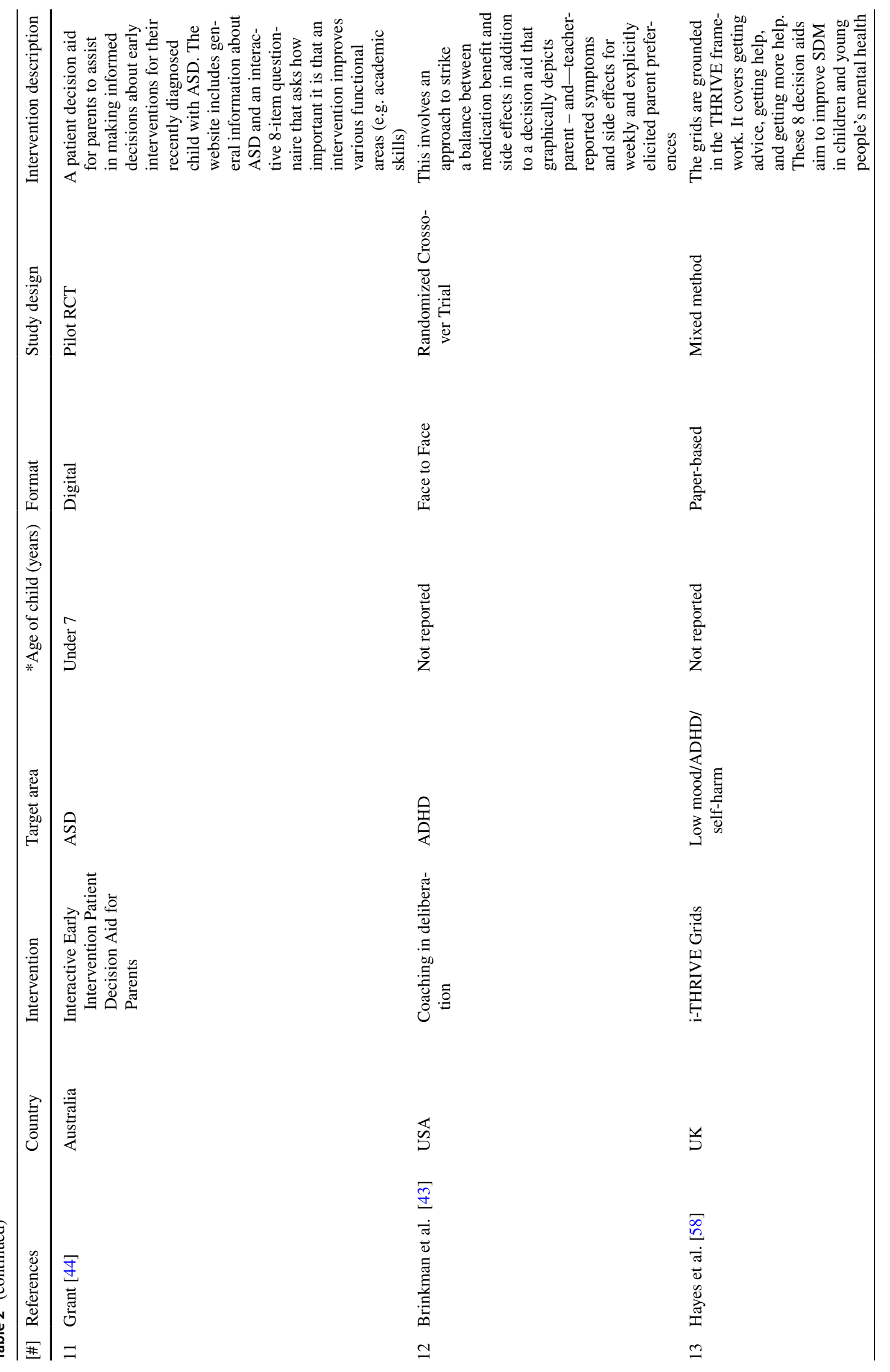




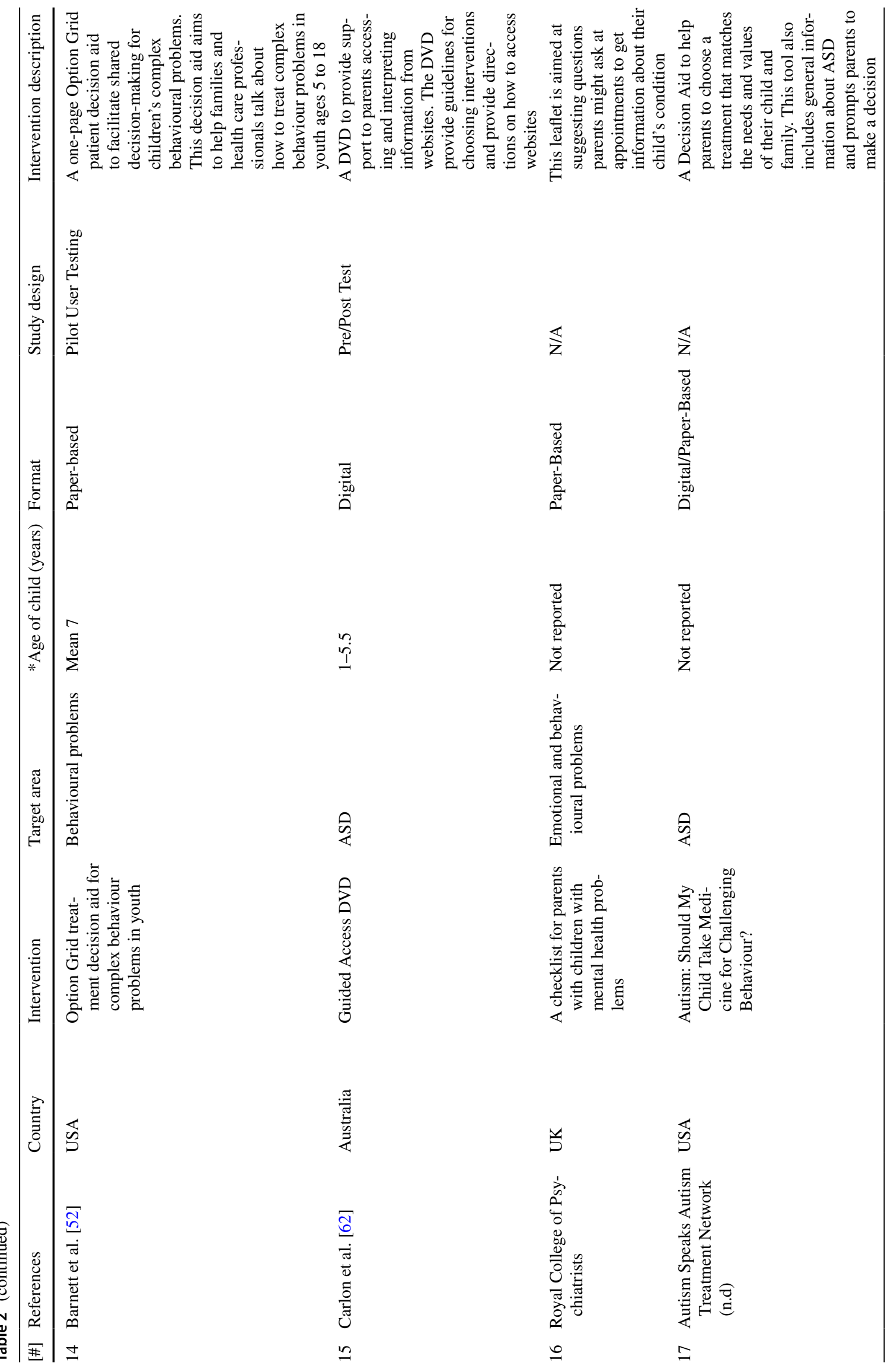




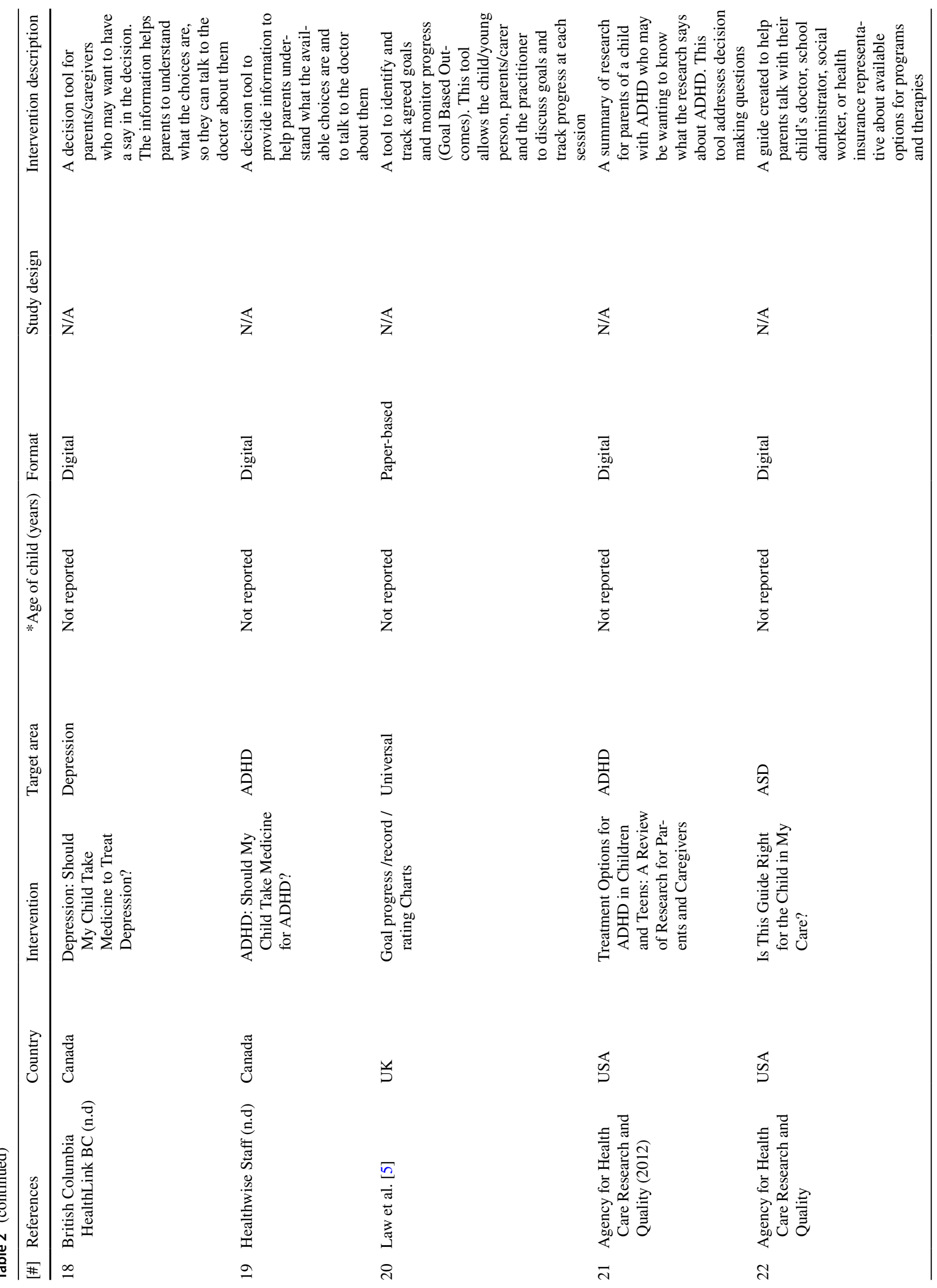


Of the 23 interventions identified, 8 were targeted at services providing care for children with ADHD, 5 were targeted at services providing care for children with ASD, 6 were for services providing care for emotional and behavioural disorders (EBD), 5 were for universal mental health care and 1 for self-harm.

Table 2 summarises the characteristics of these interventions without any hierarchical order.

Question \#2: Which of the SDM elements are addressed in these interventions?

The interventions met an average of 4.57 (SD 1.93) SDM elements. Of the 23 interventions, 61\% (14) included the capacity to "explain the problem", $87 \%$ (20) to "present options", $83 \%$ (19) to "discuss pros and cons", $61 \%$ (14) to explore "values, goals and preferences", $22 \%$ (5) to check service user's "ability and self-efficacy", $61 \%$ (14) to allow professionals to "make recommendations", $39 \%$ (9) to "check understanding" of the available options, $39 \%$ (9) to allow users to "make or defer decision", and 4\% (1) to "arrange follow-up" if unable to make a decision at the moment or to review the decision that was made.

All of the interventions included at least two of the SDM elements. The majority $(n=10)$ of the interventions were rated as low-SDM, while 8 interventions were rated as medium-SDM, and 5 were rated as high-SDM. None of the interventions met all nine SDM criteria. Only $20 \%(1 / 5)$ of the interventions rated as high were evaluated, while $87.5 \%(7 / 8)$ of those rated as medium and $70 \%$ (7/10) of those rated as low were evaluated. The more comprehensive interventions (i.e. rated as high) included most of the elements of SDM except for "arranging followup". Interventions rated as medium mostly met "explain the problem", "make recommendation", "present options", "discuss pros and cons" and "explore values, goals and preferences" elements, with fewer opportunities to "discuss ability and self-efficacy", "check understanding", "make or defer decision" and "arrange follow-up". Interventions rated as low mostly met "explain the problem", "present options" and "discuss pros and cons" with some opportunities to "explore values, goals and preferences". However, these interventions less often provided opportunities to "discuss ability and self-efficacy", "make recommendations", "check understanding", "make or defer decision" and "arrange follow-up". Table 3 summarises the results of the SDM elements checks agreed by SL and JEC.

Question \#3: What are the barriers and facilitators to usage and implementation?

Findings of this review suggest that factors such as time, accessibility, and appropriateness of the intervention were common themes identified as influencing usage and implementation of SDM interventions. These themes are encompassed in the two categories: facilitators and barriers. 


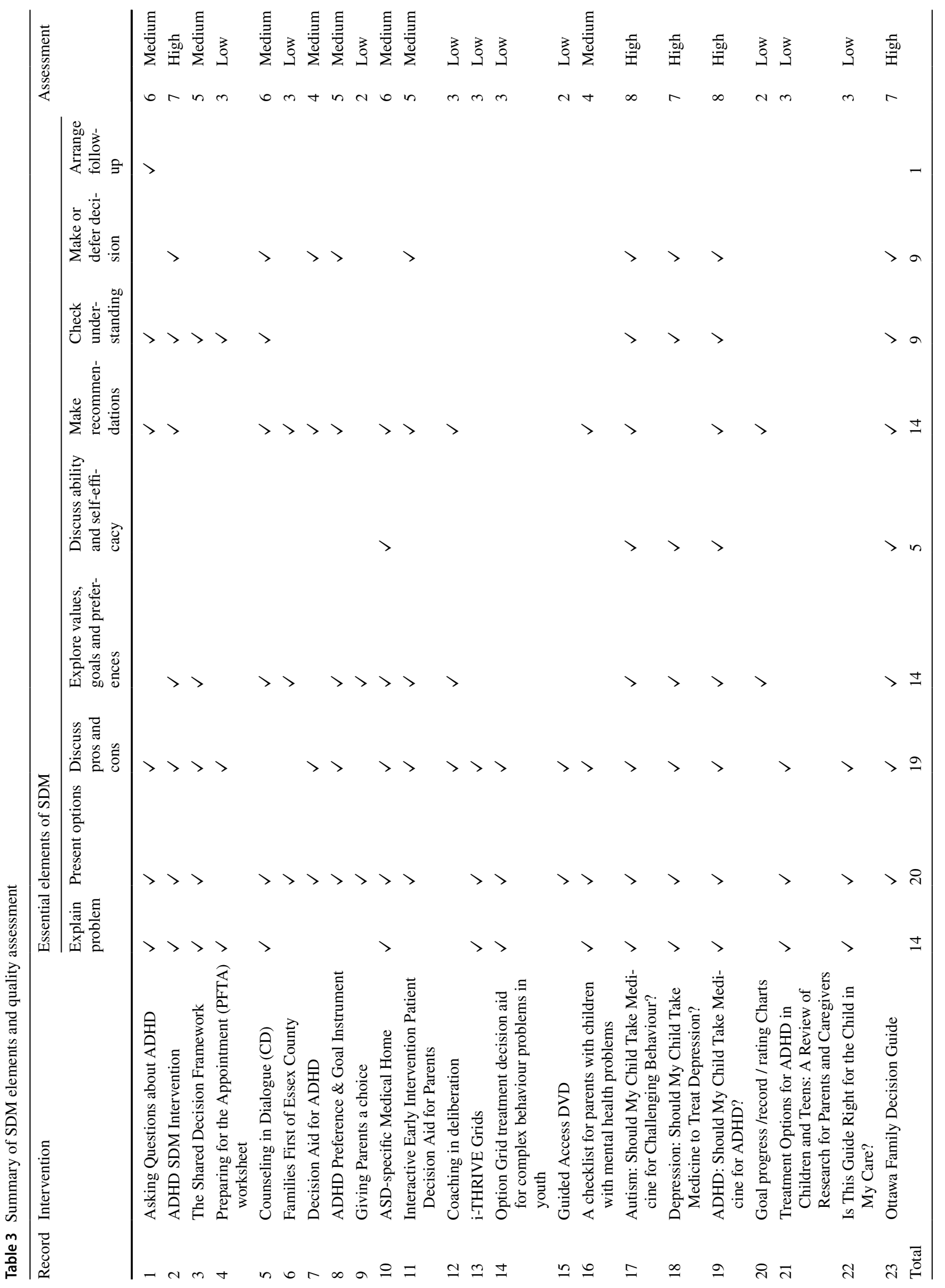




\section{Facilitators}

Factors influencing the usage of interventions varied across the different modalities (e.g. face-to-face vs. paperbased) and purpose (e.g. to provide information vs. to improve communication). For instance, parents expressed that they were interested in using the QPL because it was clear, easy to understand, and made it easier for them to ask questions. Most parents also indicated that the length of the QPL was "just right" and suggested that they would benefit most from the resource if it was provided soon after diagnosis [3]. Additionally, for the ADHD SDM intervention, which involved using choice cards and booklets, not having an increase in the length of the appointments was another factor encouraging usage [39]. However, feedback from families and service providers suggested that web interventions can save time, increase the efficiency of the process [53], and provide parents with information prior to sessions [54]. Parents involved in the Counseling in Dialogue study also appreciated the visualised form of information which supported their understanding. Findings across studies highlighted that knowing parents' preferences may boost participant engagement and inform SDM [55, 56, 57].

Clinicians highlighted that one factor encouraging the use of the intervention was the minimal training requirement. Similar to parents, clinicians were also happy with no increase in the duration of consultations. Therefore, clinicians were more inclined to use the intervention if it did not affect the flow of the consultation, or strain time or staff resources [39]. Additionally, clinicians who participated in the evaluation of the i-THRIVE Grids expressed the ease of use and not detracting from practice as facilitators [58]. Another influencing factor was the clarity and appropriateness of language as indicated by participants in the study of the Option Grid treatment decision aid. That article also highlighted that clinicians appreciated interventions including information that was credible and reliable, and like other interventions, if the resources did not result in any additional time burden [59].

\section{Barriers}

The theme of the appropriateness of the intervention was further highlighted in the article describing the Shared Decision Framework [53]. Families and service providers involved in that study expressed concerns about paperwork loads and power struggles arising from the involvement of youth in decision making [53]. Similarly, the study on the PFTA worksheets highlighted (increased) disagreement among dyads (parent and child) [60]. Findings also suggest that not giving parents a preference choice resulted in a higher chance of drop out of treatment [59].

Similar to the Shared Decision Framework, accessibility was also important to clinicians using the i-THRIVE Grids, who preferred them to be electronic for ease of access, suggesting paperwork overload as a barrier to usage [53, 58]. Another barrier to the usage of SDM interventions was highlighted in the Families First of Essex County study, which suggested that not having the availability of services and the capacity to coordinate services among their providers hindered its use [61]. Findings from the evaluation of the Interactive Early Intervention Patient Decision Aid for Parents also suggested that clinicians feared there would be a chance of information overload for parents [44]. Similar to parents' concerns, some clinicians thought that the use of the i-THRIVE Grids and the Option Grid treatment decision aid added to the already packed schedule of service users, therefore, making them 'burdensome' and overwhelming $[58,59]$.

Question \#4: What is the evidence for usefulness and acceptability of these interventions?

\section{Usefulness}

There is evidence for 11 of the 23 interventions reporting on whether users of the interventions found it helpful or useful. Descriptions of the 11 interventions (1-5, 7, 10, 11, 13-15) are provided in Table 2. Overall, the interventions were identified as useful. Users $(n=17)$ of the QPL found it useful, and qualitative findings indicated that parents felt the QPL would address some difficulties they experienced during consultations. Parents also indicated that the booklet contained questions that were useful [3]. Early feedback from implementing the Shared Decisions Framework tools and methods indicated that youths, parents, and service providers appreciated the value in SDM and the questions on the tools [53, 60]. Similarly, the evaluation of Counseling in Dialogue resulted in parents' understanding of the information, participation in treatment planning, and promoted an active role in decision making [54] indicating positive outcomes. Parents also described the i-THRIVE Grids as useful because the grids provided reliable information that accurately covered the range of available treatments and made them feel empowered [58].

Similar to parents, the clinicians also found the i-THRIVE grids helpful as a reminder of available options, and the users of the Option Grid treatment decision aid also indicated that the information provided was helpful [59]. More specifically, parents suggested the time in which the intervention was received was important as also suggested in 
relation to the Guided Access DVD, which was described as being useful for parents with a recent diagnosis [62].

The usefulness of the interventions to help parents prepare for appointments was a common theme across studies $[53,58,59,60,63]$ as the interventions were seen as convenient, flexible, and valuable to parents' lifestyle [53, 54]. Furthermore, the evaluation of the Counseling in Dialogue intervention found that the visualization elements of the intervention were helpful in supporting parents' understanding of the information [54] and the Interactive Early Intervention Patient Decision Aid for Parents pilot study highlighted that some parents found the intervention overall useful [44], The usefulness of the intervention was further highlighted by parents in the evaluation of the ASD-specific Medical Home intervention who reported experiencing fewer unmet needs, and an improvement in SDM (5.89 vs $4.03, p<0.05)$ than the control group. However, that study reported marginal statistical significance between the groups for unmet needs (5.95 vs 5.17, $p=0.067$ ) [64].

Clinicians indicated that the QPL helped parents initiate discussions about difficult topics and helped (or will help) parents in making decisions [3]. Overall, $71 \%$ of physicians in the evaluation of the ADHD SDM choice cards and booklets found the information extremely helpful and acceptable for use by parents [39]. Similar to parents, the therapist also considered the Counseling in Dialogue intervention to be a convenient and valuable method [54] and clinicians in the qualitative study of the i-THRIVE Grids suggested the grids were useful in the context of assessment clinics and 'intrinsically useful' to service users [58]. Clinicians also found the Option Grid treatment decision aid useful in structuring the session and reducing the burden related to paper handouts [59].

\section{Acceptability}

Eight of the twenty-three evaluated interventions reported on acceptability. Descriptions of the 8 interventions (1, 2, $4,7,10,13-15)$ are provided in Table 2 . The interventions were generally acceptable by users. For example, the QPL was well-received by participants in the study and resulted in a mean satisfactory score of 9.5 on a 10 point scale measure. Results showed that all parents were very satisfied or satisfied with the use of the QPL. The paediatricians also agreed that the QPL was acceptable for use by families and indicated that they would be happy to use it as part of their practice [3]. In the evaluation of the choice cards and booklets of the ADHD SDM Intervention, physicians indicated the resources were acceptable for use by families and $86 \%$ indicated that they would recommend it [39]. Similarly, parents responded positively to using the PFTA worksheets and despite some parents reporting moderate levels of satisfaction, some were eager to use it again for future appointments [13].

The decision aid for ADHD received average feedback ratings on whether users were satisfied with the decision aid itself and users reported moderate satisfaction with the information received via the tool [63]. Participants in the intervention group for the ASD-specific Medical Home study were more satisfied than those in the control group (6.49 vs $4.98, p<0.01$ ) [64]. Additionally, a parent in the qualitative study of the i-THRIVE Grids highlighted satisfaction with the intervention as it 'allowed her to make the decision that was right for her family' [58]. All participants using the Guided Access DVD indicated that they would recommend the intervention to others and some of the parents highlighted that they were very likely to continue using the tool [62]. Although interventions were acceptable, some parents and clinicians who used the Option Grid highlighted that the resources needed to be used during sessions because as a stand-alone intervention parents may feel overwhelmed by the amount of information [59].

\section{Discussion}

This scoping review was designed and carried out to identify and examine parent-targeted SDM interventions to inform practice and the development and implementation of future decision support tools. This study identified a total of 23 interventions for use by parents of children with mental health difficulties. The findings of this review suggest that interventions targeting parents met on average 4.57 (SD 1.93) essential elements of SDM and have received favourable responses to usage (acceptability and usefulness). The factors influencing usage and implementation of the interventions emerged as three overarching themes: time (e.g. increase in session times), accessibility (e.g. easily available via the web), and appropriateness of the intervention (e.g. easy to use and understand).

The review by Cheng et al. [30], examining SDM interventions for children and young people, also identified 12 of the interventions that our study found, and conducted similar quality checks using the Makoul and Clayman [36] elements which coincide with our findings. However, it must be noted that the nine elements of SDM were developed based on the literature reviewed in adult physical health settings. Therefore, applying this model to CAMHS may require more involvement from service users within CAMHS to understand how to include these elements in the interventions. With the uniqueness of the triad in CAMHS, even more research is needed to ensure these elements can be included in the development of interventions to support the SDM process. Additionally, the higher number of interventions "presenting options" but fewer "arranging follow up" can be 
explained as an immediate approach to medicinal decision making, which is mostly required in physical health. With more chronic conditions in mental health, the "arrange follow up" component may be quite useful for this population and developers can consider this going forward.

Interventions were targeted at services providing care for children with ADHD, ASD, EBD, universal CAMHS, or self-harm. This finding is also consistent with previous reviews [30,65], highlighting that most interventions in CAMHS target these disorders. This is not surprising as statistics show one in eight (12.8\%) of 5-19-year-olds have at least one mental health disorder [66]. Additionally, findings from a 30,000 children study found that just under one in five children and young people indicated they were experiencing emotional problems and the same was seen for behavioural problems [67]. Therefore, it is noted that parents of children with these mental health difficulties will be faced with making a wide range of decisions.

Previous research in this area highlighted barriers and facilitators to person-centred care in CAMHS [31]. However, this review aimed to investigate further, to discover if there were any factors specific to the use of SDM interventions by parents. Findings were consistent with the previous literature in both physical and mental health regarding the general importance of information sharing $[31,68]$ as a facilitator. Parents appreciated having information from a variety of sources to help make decisions [33, 39]. However, as this review also highlighted, the information should be appropriate, for example in a language that is jargon-free and understandable for service users [31, 68]. Knowing the types of information parents need and how to use the right media to effectively communicate the relevant information can aid parents in decision making [69, 70, 71].

Another facilitator highlighted was time efficiency, for example in being able to prepare for appointments ahead of the session. This can be favourable to parents as they are usually faced with long waiting times and time-consuming evaluations [72]. Therefore, the time spent waiting will be occupied with preparations for upcoming appointments. Additionally, accessibility of the interventions was important, for example, some parents found web-based interventions to be appealing. Although there is growing evidence to support technology in health care settings [73], more evidence is needed to investigate parents' preference for using digital interventions as a stand-alone or integrated into face-to-face sessions to support their children. From the clinician's perspectives, SDM support interventions were likely to be used if they required minimal training and had no increase in the duration of the consultations. There has been little research to date concerning clinicians' time as a resource [74]. However, there have been increasing emphasis on time and efficiency in health care delivery [75]. Therefore, having interventions that can be used during and within sessions can impact both clinicians' and parents' satisfaction with services by increasing efficiency.

In line with previous findings from similar reviews, not all interventions identified were evaluated [30, 38]. This study found that 15 (65\%) of the included interventions had associated research publications. Therefore, reporting on usefulness and acceptability for all interventions is limited, and it is, therefore, difficult to recommend their use. The increase in commercially developed interventions leaves empirical studies lagging behind. This is concerning, given the emotional state of this population. Parents of children with mental health issues report high levels of parenting stress [76] and, therefore, caution should be taken when implementing new interventions to ensure sufficient support is given throughout the decision-making process. Rigorous and ecologically valid empirical studies should be conducted to test these interventions before implementing into practice.

Service users and service providers found interventions to be useful for the decision-making process. This is consistent with existing literature as SDM has been widely advocated across health settings, patient populations and policy [22, 24]. One reason highlighted for the usefulness of the interventions was the ability to provide or facilitate information sharing. This again corroborates previous findings that information seeking is a primary element of the journey parents undergo post-diagnosis of a child with a mental health disorder [77]. However, it is noted that information needs may change at different periods [44] and information only may not be sufficient for parents [33]. Therefore, additional support needs should be offered at various stages.

Similarly, clinicians found interventions to be useful as it facilitated discussion. In pediatric health settings, health professionals welcome additional resources that provide access to information at the convenience of parents, and outside of the clinical session [78]. As a result of this, parents can be better prepared for appointments allowing for further discussions between parents and clinicians. In CAMH settings, similar findings indicate that keeping reports and tracking progress leads to shared work between the therapist, young person and family, which can lead to better agreement and working alliance in therapy [5].

Eight interventions had supporting evidence to indicate overall satisfaction with the use of the intervention. This is supportive of previous studies that highlight parents' need for additional support $[79,80]$ to make informed decisions. Therefore, the findings of this review confirm that parents were satisfied with receiving more information through SDM interventions. These findings suggest that once parents are provided with the right kind of support, they will feel more included by services and their own anxieties of not being informed will decrease [81]. Clinicians also responded favourably to using SDM interventions suggesting that services have a willingness 
to implement PCC as recommended in policy guidelines for health care $[24,25,82]$.

\section{Strengths and limitations}

This review has major strengths, such as, including a very broad search strategy similar to those already published [30, 31] and a comprehensive concept-specific tool for assessing essential elements of SDM [36]. However, there are some limitations to be considered when interpreting the findings of this scoping review. Firstly, of the 23 interventions, only 9 were identified through the database searching. This can be due to the lack of a standardized definition (e.g. decision aid, decision support tools, and decision support interventions) used for SDM [36]. Although this review used a very broad search strategy and two independent reviewers, it was possible that some records may have been missed. Secondly, not all the interventions identified were evaluated and those that were evaluated lacked homogeneity in terms of study design, SDM outcome measure, mode of delivery, and target population making it difficult to synthesize.

For this review, we examined the essential elements of SDM in interventions using the framework by Makoul and Clayman [36]. Although these guidelines are useful in providing an overall sense of whether the intervention is achieving its purpose, the behaviours associated with each criterion may differ making it difficult to standardize [83]. Additionally, the lack of detail and heterogeneous study designs made it difficult to objectively conduct an assessment using this tool as it was uncertain how the intervention was used within the client-clinician interactions. An alternative assessment tool that can be considered in future studies is the International Patient Decision Aid Standards (IPDAS), which provides a minimal set of standards for qualifying as a decision aid, and for judging the quality of decision aids [84]. However, the IPDAS may not have been suitable for the current study as the authors aimed to assess the presence of essential elements of SDM in relations to the SDM process and not the quality of the intervention itself. Assessing the quality of the evidence underlying the interventions, including development and evaluation, may have required contacting the interventions' developers, which was beyond the scope of this review. Furthermore, the results of this review are only up to date as of December 2018. Nonetheless, it is believed that this scoping review provides important information, and it is the most rigorous in the area of parent-targeted SDM in CAMH settings that the authors are currently aware of.

\section{Future directions and recommendations}

There is an urgent need for adequately powered and rigorously designed RCTs to evaluate the efficacy of parenttargeted SDM support interventions. Conducting such studies can support researchers in identifying and comparing specific elements that best support the SDM process in future review studies. Based on findings from this review, some broad key recommendations are suggested to develop and implement SDM support interventions. First, it is recommended that interventions not reaching IPDAS criteria [84] report on elements of SDM involved in the intervention, so end users can obtain additional support to supplement the intervention if needed. Second, as identified by some service users and service providers, interventions should be web-based or online to avoid paperwork overload. Just as important, it is recommended that new interventions require minimal training for both providers and users of the interventions and that the interventions be made accessible via an open access repository of SDM interventions. Another recommendation is that the content and usage of the interventions be easy to understand. Finally, it is recommended that service providers receive the necessary support and knowledge to be confident in recommending or using decision support tools with service users.

\section{Conclusion}

In conclusion, this scoping review provided a broad overview of parent-targeted decision support interventions used in CAMHS. It is noted that further research is needed to evaluate and compare parents' preferences for decision support interventions. At a minimum, this review may serve to provide awareness of available parentinvolved SDM support interventions and inform guidelines for the development, implementation, and usage of new interventions.

Acknowledgements This project has received funding from the European Union's Horizon 2020 research and innovation programme under the Marie Skłodowska-Curie grant agreement No. 722561. We thank Heather Chester from the University College Library for guidance during the literature searching. We also thank Miles Weekes for support at the time of writing the manuscript.

Author contributions JEC, MW and SL conceived the study during supervision meetings. SL coordinated the study and was responsible for screening, quality checks, data extraction and drafting the manuscript. BP piloted the eligibility criteria, crosschecked the included records and verified the data extracted. JEC participated in the quality checking. DH edited the manuscript and provided studies/interventions for inclusion. All authors read and approved the final manuscript. 


\section{Compliance with ethical standards}

Conflict of interest All authors declare that they have no conflicting financial interests. One of the authors of this review, $\mathrm{DH}$, is also the developer of one of the included interventions (i-THRIVE Grids). MW and JEC were also involved in publications arising from data collected using the Goal Based Outcomes tool, as part of the Child Outcomes Research Consortium (CORC).

Open Access This article is licensed under a Creative Commons Attribution 4.0 International License, which permits use, sharing, adaptation, distribution and reproduction in any medium or format, as long as you give appropriate credit to the original author(s) and the source, provide a link to the Creative Commons licence, and indicate if changes were made. The images or other third party material in this article are included in the article's Creative Commons licence, unless indicated otherwise in a credit line to the material. If material is not included in the article's Creative Commons licence and your intended use is not permitted by statutory regulation or exceeds the permitted use, you will need to obtain permission directly from the copyright holder. To view a copy of this licence, visit http://creativecommons.org/licenses/by/4.0/.

\section{References}

1. Wolpert M, Harris R, Hodges S, Fuggle P, James R, Wiener A, Mckenna C, Law D, York A, Jones M, Fonagy P, Fleming I, Munk S (2016) Thrive elaborated. Second edition. Press CAMHS, UK

2. Ackerman SJ, Duff SB, Dennehy PH, Mafilios MS, Krilov LR (2001) Economic impact of an infection control education program in a specialized preschool setting. Pediatrics 108(6):E102

3. Ahmed R, McCaffery KJ, Silove N, Butow P, Clarke S, Kohn M, Aslani P (2017) The evaluation of a question prompt list for attention-deficit/hyperactivity disorder in pediatric care: a pilot study. Res Soc Admin Pharm 13(1):172-186. https://doi.org/10.1016/j. sapharm.2016.01.009

4. Bradley J, Murphy S, Fugard A, Nolas S, Law D (2013) What kinds of goals do children and young people set for themselves in therapy? Developing a goals framework using CORC data. Child Fam Clin Psychol Rev 1(1):8-18

5. Law D, Jacob J (2015) Goals and goal based outcomes (GBOs): some useful information (Third ed.). London

6. Berger ZD, Brito JP, Ospina NS, Kannan S, Hinson JS, Hess EP, Haskell H, Montori VM, Newman-Toker DE (2017) Patient centred diagnosis: sharing diagnostic decisions with patients in clinical practice. BMJ. https://doi.org/10.1136/bmj.j4218

7. Barber AJ, Tischler VA, Healy E (2006) Consumer satisfaction and child behaviour problems in child and adolescent mental health services. J Child Health Care 10(1):9-21. https://doi. org/10.1177/1367493506060200

8. Biering P (2010) Child and adolescent experience of and satisfaction with psychiatric care: a critical review of the research literature. J Psychiatr Ment Health Nurs 17(1):65-72. https://doi.org/1 0.1111/j.1365-2850.2009.01505.x

9. Godley SH, Fiedler EM, Funk RR (1998) Consumer satisfaction of parents and their children with child/adolescent mental health services. Eval Program Plann 21(1):31-45. https://doi. org/10.1016/S0149-7189(97)00043-8

10. Jensen-Doss A, Weisz JR (2008) Diagnostic agreement predicts treatment process and outcomes in youth mental health clinics. $\mathrm{J}$ Consult Clin Psychol 76(5):711-722

11. Jensen-Doss A, Youngstrom EA, Youngstrom JK, Feeny NC, Findling RL (2014) Predictors and moderators of agreement between clinical and research diagnoses for children and adolescents. J Consult Clin Psychol 82(6):1151-1162. https://doi.org/10.1037/ a0036657

12. Kaplan S, Busner J, Chibnall J, Kang G (2001) Consumer satisfaction at a child and adolescent state psychiatric hospital. Psychiatr Serv (Washington, DC) 52(2):202. https://doi.org/10.1176/appi. ps.52.2.202

13. O'Brien KH, Hernandez L, Spirito A (2015) Parental monitoring affects the relationship between depressed mood and alcoholrelated problems in adolescents. Subst Abus 36(1):82-84

14. Simmons MB, Hetrick SE, Jorm AF (2013) Making decisions about treatment for young people diagnosed with depressive disorders: a qualitative study of clinicians' experiences. BMC Psychiatry 13:16. https://doi.org/10.1186/1471-244x-13-335

15. Simmons MB, Hetrick SE, Jorm AF (2011) Experiences of treatment decision making for young people diagnosed with depressive disorders: a qualitative study in primary care and specialist mental health settings. BMC Psychiatry 11:13. https ://doi.org/10.1186/1471-244x-11-194

16. Stuntzner-Gibson D, Koren P, Dechillo N (1995) The youth satisfaction questionnaire: what kids think of Se. Fam Soc 76(10):616. https://doi.org/10.1177/104438949507601004

17. Vanheusden K, Mulder CL, van Der Ende J, van Lenthe FJ, Mackenbach JP, Verhulst FC (2008) Young adults face major barriers to seeking help from mental health services. Patient Educ Couns 73(1):97-104. https://doi.org/10.1016/j. pec.2008.05.006

18. Yeh M, Weisz JR (2001) Why are we here at the clinic? Parentchild (dis)agreement on referral problems at outpatient treatment entry. J Consult Clin Psychol 69(6):1018-1025. https://doi. org/10.1037/0022-006X.69.6.1018

19. Fulford KWM (2008) Values-based practice: a new partner to evidence-based practice and a first for psychiatry? Mens Sana Monogr 6(1):10-21. https://doi.org/10.4103/0973-1229.40565

20. Laitner S (2012) Shared decision making leads to a better patient experience. The Guardian

21. Langer DA, Jensen-Doss A (2018) Shared decision-making in youth mental health care: using the evidence to plan treatments collaboratively. J Clin Child Adolesc Psychol 47(5):821-831. https://doi.org/10.1080/15374416.2016.1247358

22. Wolpert M, Hoffman J, Abrines N, Feltham A, Baird L, Law D, Martin K, Constable A, Hopkins K (2012) Closing the gap through changing relationships. Final report for closing the gap through changing relationships. The Health Foundation, London

23. Charles C, Gafni A, Whelan T (1997) Shared decision-making in the medical encounter: what does it mean? (or it takes at least two to tango). Soc Sci Med 44(5):681-692. https://doi.org/10.1016/ S0277-9536(96)00221-3

24. National Institute for Health and Care Excellence (2019) Shared decision making. https://www.nice.org.uk/about/what-we-do/ our-programmes/nice-guidance/nice-guidelines/shared-decisionmaking. Accessed 28 Feb 2019

25. Institute of Medicine (2001) Crossing the quality chasm: a new health system for the 21 st century. The National Academies Press, Washington, DC. https://doi.org/10.17226/10027

26. Officer CM (2014) Annual report of the Chief Medical Officer (2013) Public mental health priorities: investing in the evidence. Department of Health, London

27. Dicé F, Dolce P, Freda MF (2016) Exploring emotions and the shared decision-making process in pediatric primary care. Mediterr J Clin Psychol 4:3. https://doi. org/10.6092/2282-1619/2016.4.1312

28. Creswell C, Cartwright-Hatton S, Rodriguez N (2013) Working collaboratively with parents and carers in cognitive behaviour therapy (CBT). In: Graham P, Reynolds S (eds) Cognitive 
behaviour therapy for children and families, 3rd edn. Cambridge University Press, New York, pp 91-109

29. Wolpert M, Doe J, Elsworth J (2005) In: Graham P (ed) Cognitive behaviour therapy for children and families, 2nd edn. Cambridge University Press, New York, pp 103-120

30. Cheng H, Hayes D, Edbrooke-Childs J, Martin K, Chapman L, Wolpert M (2017) What approaches for promoting shared decision-making are used in child mental health? A scoping review. Clin Psychol Psychother 24(6):O1495-O1511. https://doi. org/10.1002/cpp.2106

31. Gondek D, Edbrooke-Childs J, Velikonja T, Chapman L, Saunders F, Hayes D, Wolpert M (2017) Facilitators and barriers to personcentred care in child and young people mental health services: a systematic review. Clin Psychol Psychother 24(4):870-886. https ://doi.org/10.1002/cpp.2052

32. Ottawa Health Research Institute (2014) Implementation toolkit. https://decisionaid.ohri.ca/implement.html. Accessed 22 Mar 2019

33. Jackson C, Cheater FM, Reid I (2008) A systematic review of decision support needs of parents making child health decisions. Health Expect 11(3):232-251. https://doi.org/10.111 1/j.1369-7625.2008.00496.x

34. Lipstein EA, Lindly OJ, Anixt JS, Britto MT, Zuckerman KE (2016) Shared decision making in the care of children with developmental and behavioral disorders. Matern Child Health J 20(3):665-673. https://doi.org/10.1007/s10995-015-1866-z

35. Abrines-Jaume N, Midgley N, Hopkins K, Hoffman J, Martin K, Law D, Wolpert M (2016) A qualitative analysis of implementing shared decision making in Child and Adolescent Mental Health Services in the United Kingdom: stages and facilitators. Clin Child Psychol Psychiatry 21(1):19-31. https://doi.org/10.1177/13591 04514547596

36. Makoul G, Clayman ML (2006) An integrative model of shared decision making in medical encounters. Patient Educ Couns 60(3):301-312. https://doi.org/10.1016/j.pec.2005.06.010

37. Feenstra B, Boland L, Lawson ML, Harrison D, Kryworuchko J, Leblanc M, Stacey D (2014) Interventions to support children's engagement in health-related decisions: a systematic review. BMC Pediatr 14:109-109. https://doi.org/10.1186/1471-2431-14-109

38. Wyatt KD, List B, Brinkman WB, Prutsky Lopez G, Asi N, Erwin P, Wang Z, Domecq Garces JP, Montori VM, LeBlanc A (2015) Shared decision making in pediatrics: a systematic review and meta-analysis. Acad Pediatr 15(6):573-583. https://doi. org/10.1016/j.acap.2015.03.011

39. Brinkman WB, Hartl Majcher J, Poling LM, Shi G, Zender M, Sucharew H, Britto MT, Epstein JN (2013) Shared decisionmaking to improve attention-deficit hyperactivity disorder care. Patient Educ Couns 93(1):95-101. https://doi.org/10.1016/j. pec.2013.04.009

40. Khan KS, Kunz R, Kleijnen J, Antes G (2003) Five steps to conducting a systematic review. J R Soc Med 96(3):118-121. https:// doi.org/10.1177/014107680309600304

41. Arksey H, O'Malley L (2005) Scoping studies: towards a methodological framework. Int J Soc Res Methodol 8(1):19-32. https ://doi.org/10.1080/1364557032000119616

42. Edwards P, Clarke M, DiGuiseppi C, Pratap S, Roberts I, Wentz R (2002) Identification of randomized controlled trials in systematic reviews: accuracy and reliability of screening records. Stat Med 21(11):1635-1640

43. Brinkman WB, Froehlich T, Sucharew H, Simon J, Langberg J, Expstein J (2013) Effect of an explicit values clarification exercise on parental decision making and subsequent medication use following completion of an N-of- 1 methylphenidate trial among children with ADHD. Paper presented at the International Shared Decision Making Conference, Peru
44. Grant N (2016) Assisting parents of children with autism to make intervention decisions by improving their health literacy about evidence. The University of Queensland,

45. Hoffman J (2015) Biostatistics for medical and biomedical practitioners. Meta-analysis. Academic Press, New York

46. Popay J, Roberts H, Sowden A, Petticrew M, Arai L, Rodgers M, Britten N, Roen K, Duffy S (2006) Guidance on the conduct of narrative synthesis in systematic reviews

47. Ahmed R, McCaffery KJ, Silove N, Butow P, Clarke S, Kohn M, Aslani P (2017) The evaluation of a question prompt list for attention-deficit/hyperactivity disorder in pediatric care: A pilot study. Res Soc Adm Pharm 13(1):172-186

48. O'Brien M, Holmes C, Chapman K, Rosen M, Lee J, Crickard E (2015) Innovations in Practice: Supporting parent and teen communication during outpatient psychotropic medication appointments. Child Adolesc Ment Health 20(2):107-111

49. Westermann G, Verheij F (2009) Counseling in the Dutch youth mental health care: A survey. Tijdschrift voor Psychiatrie 51(5):333-338

50. Fiks AG, Mayne S, Localio AR, Alessandrini EA, Guevara JP (2011) Shared decision-making and health care expenditures among children with special health care needs. Pediatrics 129(1):99-107

51. Golnik A, Scal P, Wey A, Gaillard P (2012) Autism-specific primary care medical home intervention. J Autism Dev Disord 42(6): 1087-1093

52. Barnett ER, Boucher EA, Daviss WB, Elwyn G (2018) Supporting shared decision-making for children's complex behavioral problems: development and user testing of an option grid $^{\mathrm{TM}}$ decision aid. Community Ment Health J 54(1):7-16

53. Crickard E, O’Brien M, Rapp C, Holmes C (2010) Developing a framework to support shared decision making for youth mental health medication treatment. Community Ment Health J 46(5):474-481. https://doi.org/10.1007/s10597-010-9327-z

54. Westermann GMA, Verheij F, Winkens B, Verhulst FC, Van Oort FVA (2013) Structured shared decision-making using dialogue and visualization: a randomized controlled trial. Patient Educ Couns 90(1):74-81. https://doi.org/10.1016/j.pec.2012.09.014

55. Gewirtz AH, Lee SS, August GJ, He Y (2018) Does giving parents their choice of interventions for child behavior problems improve child outcomes? Prev Sci 20(1):78-88. https://doi.org/10.1007/ s11121-018-0865-x

56. He Y, Gewirtz A, Lee S, Morrell N, August G (2016) A randomized preference trial to inform personalization of a parent training program implemented in community mental health clinics. Transl Behav Med 6(1):73-80. https://doi.org/10.1007/s1314 2-015-0366-4

57. He Y, Gewirtz AH, Lee S, August G (2018) Do parent preferences for child conduct problem interventions impact parenting outcomes? A pilot study in community children's mental health settings. J Marit Fam Ther 44(4):716-729. https://doi.org/10.1111/ jmft. 12310

58. Hayes D, Town R, Lemoniatis E (2018) Developing and piloting i-THRIVE grids

59. Barnett ER, Boucher EA, Daviss WB, Elwyn G (2018) Supporting shared decision-making for children's complex behavioral problems: development and user testing of an option Grid ${ }^{\mathrm{TM}}$ decision aid. Community Ment Health J 54(1):7-16. https://doi. org/10.1007/s10597-017-0136-5

60. O'Brien M, Holmes C, Chapman K, Rosen M, Lee J, Crickard E (2015) Innovations in practice: supporting parent and teen communication during outpatient psychotropic medication appointments. Child Adolesc Mental Health 20(2):107-111. https://doi. org/10.1111/camh.12076

61. Evans M, Armstrong M, Thompson F, Lee J (1994) Assessing the outcomes of parent-and provider designed systems of care for 
children with emotional and behavioral disorders. Psychiatry Q 65(4):257-272

62. Carlon S, Carter M, Stephenson J (2017) Pilot study of a parent guided website access package for early intervention decision-making for autism spectrum disorder. Aust J Spec Educ 41(2):141-156. https://doi.org/10.1017/jse.2017.7

63. Ossebaard HC, van Gemert-Pijnen JEWC, Sorbi MJ, Seydel ER (2010) A study of a Dutch online decision aid for parents of children with ADHD. J Telemed Telecare 16(1):15-19. https://doi. org/10.1258/jtt.2009.001006

64. Golnik A, Scal P, Wey A, Gaillard P (2012) Autism-specific primary care medical home intervention. J Autism Dev Disord 42(6):1087-1093. https://doi.org/10.1007/s10803-011-1351-5

65. Grist R, Porter J, Stallard P (2017) Mental health mobile apps for preadolescents and adolescents: a systematic review. J Med Internet Res 19:5. https://doi.org/10.2196/jmir.7332

66. Government Statistical Service (2017) Mental health of children and young people in England. NHS Digital

67. Deighton J, Lereya T, Patalay P, Casey P, Humphrey N, Wolpert M (2018) Mental health problems in young people, aged 11 to 14 : results from the first HeadStart annual survey of 30,000 children (trans: Unit EBP)

68. Bee P, Price O, Baker J, Lovell K (2015) Systematic synthesis of barriers and facilitators to service user-led care planning. Br J Psychiatry 207(2):104-114. https://doi.org/10.1192/bjp.bp.114.15244 7

69. Brinkman WB, Sherman SN, Zmitrovich AR, Visscher MO, Crosby LE, Phelan KJ, Donovan EF (2009) Parental angst making and revisiting decisions about treatment of attention-deficit/hyperactivity disorder. Pediatrics 124(2):580. https://doi.org/10.1542/ peds.2008-2569

70. Allen B, Varela A (2015) Caregiver perceptions of clinical decision-making for the treatment of children. Community Ment Health J 51(7):828-832. https://doi.org/10.1007/s1059 7-015-9871-7

71. Allen KA (2014) Parental decision-making for medically complex infants and children: an integrated literature review. Int $\mathbf{J}$ Nurs Stud 51(9):1289-1304. https://doi.org/10.1016/j.ijnur stu.2014.02.003

72. Kalb GL, Freedman GB, Foster GC, Menon GD, Landa GR, Kishfy GL, Law GP (2012) Determinants of appointment absenteeism at an outpatient pediatric autism clinic. J Dev Behav Pediatr 33(9):685-697. https://doi.org/10.1097/DBP.0b013e3182 6c66ef

73. Montague AE, Varcin KJ, Simmons MB, Parker AG (2015) Putting technology into youth mental health practice: young people's perspectives. SAGE Open 5(2):2158244015581019. https://doi. org/10.1177/2158244015581019

74. Davidoff F (1997) Continuing medical education resources. J Gen Intern Med 12(s2):15-19. https://doi.org/10.1046/j.1525-1497.12. s2.2.x

75. Dugdale D, Epstein R, Pantilat S (1999) Time and the patientphysician relationship. J Gen Intern Med 14(S1):34-40. https:// doi.org/10.1046/j.1525-1497.1999.00263.x
76. Bitsika V, Sharpley CF, Bell R (2013) The buffering effect of resilience upon stress, anxiety and depression in parents of a child with an autism spectrum disorder. J Dev Phys Disabil 25(5):533-543. https://doi.org/10.1007/s10882-013-9333-5

77. Grant N, Rodger S, Hoffmann T (2016) Intervention decisionmaking processes and information preferences of parents of children with autism spectrum disorders. Child Care Health Dev 42(1):125-134. https://doi.org/10.1111/cch.12296

78. Delany C, Xafis V, Gillam L, Hughson J-A, Hynson J, Wilkinson D (2017) A good resource for parents, but will clinicians use it?: evaluation of a resource for paediatric end-of-life decision making. BMC Palliat Care 16(1):12. https://doi.org/10.1186/s1290 4-016-0177-5

79. Ahmed R, Raynor DK, McCaffery KJ, Aslani P (2014) The design and user-testing of a question prompt list for attention-deficit/ hyperactivity disorder. BMJ Open 4:12. https://doi.org/10.1136/ bmjopen-2014-006585

80. Fiks AG, Mayne S, Hughes CC, Debartolo E, Behrens C, Guevara JP, Power T (2012) Development of an instrument to measure parents' preferences and goals for the treatment of attention deficithyperactivity disorder. Acad Pediatr 12(5):445-455. https://doi. org/10.1016/j.acap.2012.04.009

81. Association of Young People's Health (AYPH) (2016) "There for you": the role of parents in supporting young people with mental health problems: results of a survey. https://www.youngpeopl eshealth.org.uk/wp. Accessed 22 Mar 2019

82. Health Do (2015) Future in mind: Promoting, protecting and improving ourchildren and young people's mental health and wellbeing. https://assets.publishing.service.gov.uk/government/uploa ds/system/uploads/attachment_data/file/414024/Childrens_Menta 1_Health.pdf. Accessed 22 Mar 2019

83. Towle A, Godolphin W (1999) Framework for teaching and learning informed shared decision making. BMJ 319(7212):766-771

84. International Patient Decision Aid Standards (IPDAS) Collaboration (2005). https://ipdas.ohri.ca/IPDAS_checklist.pdf. Accessed 22 Mar 2019

85. Hayes D, Edbrooke-Childs J, Town R, Wolpert M, Midgley N (2019) Barriers and facilitators to shared decision making in child and youth mental health: exploring young people and parent perspectives using the Theoretical Domains Framework. Counsell Psychother Res. https://doi.org/10.1186/s13063-019-3762-0

86. Hayes D, Edbrooke-Childs J, Town R, Wolpert M, Midgley N (2018) Barriers and facilitators to shared decision making in child and youth mental health: clinician perspectives using the Theoretical Domains Framework. Eur Child Adolesc Psychiatry. https:// doi.org/10.1007/s00787-018-1230-0

87. Bouniols N, Leclère B, Moret L (2016) Evaluating the quality of shared decision making during the patient-carer encounter: a systematic review of tools. BMC Research Notes 9(1):382. https ://doi.org/10.1186/s13104-016-2164-6 